\title{
A Rare Complication of Percutaneous Nephrolithotomy: Cerebral Infarction and Hemianopsia
}

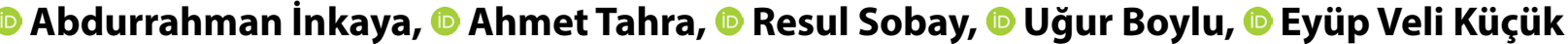

Departmant of Urology, Health Sciences University, Umraniye Training and Research Hospital, Istanbul, Turkey

\begin{abstract}
Since its description in 1976, percutaneous nephrolithotomy (PNL) has become the most common surgical technique for the management of large and complex stones in the intrarenal collecting system. A wide variety of complications can be observed, including bleeding associated with this procedure, damage to neighboring tissues and organs, infection, positional injuries, thromboembolic events, and even death. Knowing and predicting the different complications can be useful in preventing, diagnosing and preventing complications. We aimed to present the management of cerebral infarction and hemianopsia after PNL to our clinic as a case report. Keywords: Hemorrhage; infarction; PCNL; renal stone.
\end{abstract}

$\mathrm{P}$ ercutaneous nephrolithotomy (PNL) has become widespread since its first description in 1976 and has become the most prevalently used surgical technique for large and complex stones in the intrarenal collecting system ${ }^{[1]}$. In this procedure, bleeding, damage to neighboring tissues and organs, infection, positional injuries, thromboembolic events and even death may be observed ${ }^{[2]}$. Knowing and predicting different complications may be helpful in diagnosing, and preventing complications.

\section{Case Report}

A 58-year-old patient without comorbidity presented with right flank pain, and a visible right flank incision scar. The patient had undergone open surgery for right renal stone, and 7 sessions of shock wave lithitripsy (ESWL). His hemoglobin (Hb), $12.2 \mathrm{gr} / \mathrm{dL}$; hematocrit (hCT) 41\%, creatinine, $0.9 \mathrm{mg} / \mathrm{dL}$, and blood urea nitrogen $20 \mathrm{mg} / \mathrm{dL}$ values were as indicated. Whole abdominal computed tomography of the patient demonstrated a stone with dimensions of $36 \times 23 \times 21 \mathrm{~mm}$ in the pelvis of the right grade 3 hydronephrotic kidney, and multiple stones in the lower pole of the same kidney the largest one with a diameter of 17 mm (Fig. 1). DMSA (dimercaptosuccinic acid) renal scintigraphy revealed right and left split renal functions as 34, and $66 \%$, respectively, so PNL application for right kidney was decided. During operation, the lower calyx was accessed with $18 \mathrm{G}$ percutaneous needle and stones in the lower calyx and renal pelvis were fragmented and extracted with pneumatic lithotriptor. Complications did not occur during the operation which lasted approximately 90 minutes. Residual stones were present in the anterior group of the lower calyx after the operation. Two hours after the operation hb was $11.7 \mathrm{gr} / \mathrm{dL}$, and hct, 36 percent.

Postoperative $12^{\text {th }}$ hour hb was $11.5 \mathrm{gr} / \mathrm{dL}$, and hct 34.6 percent. The patient's consciousness blurred, loss of cooperation, and impaired orientation developed, he couldn't give meaningful answers to questions, and repeated the same answer. Right-sided hemianopsia was detected. Dif-

Correspondence (iletişim): Abdurrahman İnkaya, M.D. Departmant of Urology, Health Sciences University, Umraniye Training and Research Hospital, Istanbul, Turkey

Phone (Telefon): +90 2166321818 E-mail (E-posta): ainkaya@hotmail.com

Submitted Date (Başvuru Tarihi): 03.05.2018 Accepted Date(Kabul Tarihi): 22.07.2018

Copyright 2018 Haydarpaşa Numune Medical Journal

This is an open access article under the CC BY-NC license (http://creativecommons.org/licenses/by-nc/4.0/). 


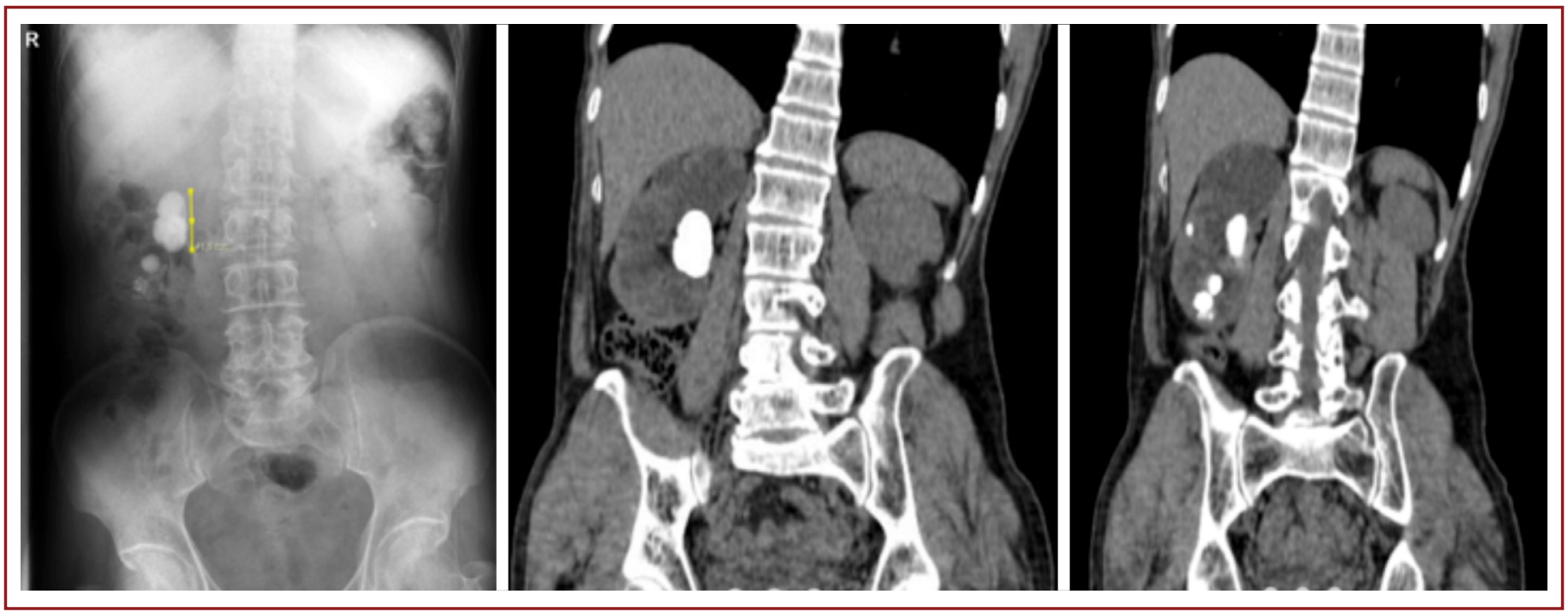

Figure 1. Preoperative KUB and computed tomographic image.

fusion magnetic resonance imaging (MRI) demonstrated patchy areas of acute infarct in the left medial cerebral inferior branch, left frontal border zone, and the right frontal segment (Fig. 2), so acetylsalicylic acid (150 mg 1x1) was initiated as a result of neurological consultation. Cardiology consultation did not indicate any cardiac pathology. Carotid and vertebrobasilar system Doppler ultrasonography did not reveal any pathology. The patient was started on $2 \times 6000 \mathrm{IU}$ of enoxaparin sodium.

After enoxaparin sodium treatment, macroscopic hematuria was seen coming from nephrostomy tube, and urethral catheter, so 3-way Foley catheter were delivered through transurethral route, and irrigation of the bladder was started. Despite transfusion, hemoglobin $(6 \mathrm{gr} / \mathrm{dL})$, and hematocrit levels (23\%) dropped down to indicated levels, therefore selective arterial angiomyolysis was planned. In the department of interventional radiology pseudoaneurysms were detected in two different segmental arteries, and selective arterial angioembolization was performed.

After the first angioembolization, hemoglobin, and hematocrit values of the patient decreased, though at a lower rate, and the patient underwent a second angioembolization for a different artery three days after the first embolization. The hemodynamic values decreased on the 5th day after the second angioembolization. Then the patient was assessed by a different interventional radiology team at another center and renal angiography was performed for the third time to embolize the proximal segmental artery (Fig. 3).

A total of 8 units of erythrocyte suspension, 4 units of fresh frozen plasma were delivered to the patient on the $18^{\text {th }}$ postoperative day and the patient who had under-

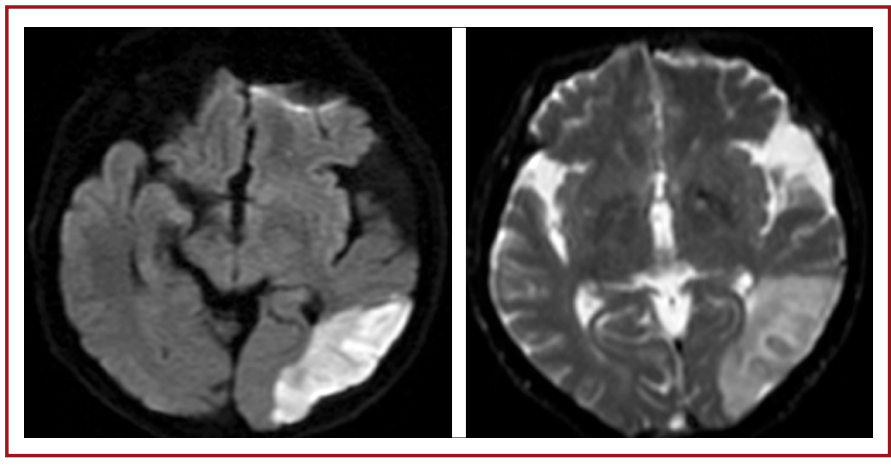

Figure 2. Appearance of the infarcted area in diffusion MRI obtained at postoperative $12^{\text {th }}$ hour.

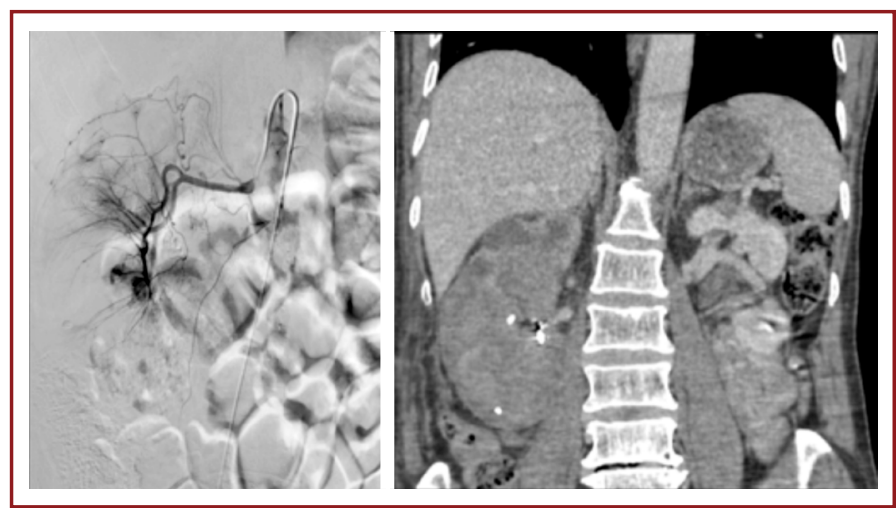

Figure 3. Computed tomographic image after renal angiography/ angioembolization and angioembolization.

gone selective arterial angioembolization for 3 times was discharged from our clinic without hematuria On the final neurological examination of the patient, he was conscious with normal cooperation and orientation. His rate of speech slowed down partially, and right - sided hemianopsia (nearly $70 \%$ loss in the visual field) was detected. 


\section{Discussion}

Following PNLs complication rates up to $83 \%$ have been reported ${ }^{[3]}$. These complications are usually minor bleedings, fever, and extravasation (in $7.2 \%$ of the cases). Hemorrhagic complications require transfusion in 11.2-17.5\% of the cases. Bleedings stemming from formation of pseudoaneurysms and arteriovenous fistulae are among the most serious complications. Success rates of up to $80 \%$ have been reported in the literature after superselective angioembolizations (SAE) performed to stop bleeding ${ }^{[4]}$. Rarely sepsis (0.3-4.7\%), colon injury (0.0-0.8\%), and pleural injury (0.0-3.1\%) have been observed ${ }^{[5]}$.

The most important factor for achieving acceptable outcomes and success in minimizing major complications in PNL is the selection of the patient who will mostly benefit from this procedure. Use of well-standardized techniques and postoperative follow-up is essential for early detection and management of complications. In PNL in terms of thromboprophylaxis, before proceeding with the surgery, determination of patient-related risk factors as age, presence of comorbidity, family history, systemic diseases, thromboembolic events, increased body mass index, and then initiation of thromboprophylaxis with low-molecular weight heparin has been recommended till complete mobilization is achieved ${ }^{[6]}$.

\section{Conclusion}

We think that a standardized algorithm for control of bleedings, and management of thromboembolism is required for thromboembolic events developed after a kind of controlled grade 4 trauma in major renal surgery where collect- ing system is entered passing through renal parenchyma as in the case of PNL These complications are rare, but management requires a serious and urgent approach.

Informed Consent: Approval was obtained from the patient. Peer-review: Externally peer-reviewed.

Conflict of Interest: None declared.

Authorship Contributions: Concept: A.I.; Design: A.T.; Data Collection or Processing: R.S.; Analysis or Interpretation: E.V.K.; Literature Search: U.B.; Writing: A.I.

Financial Disclosure: The authors declared that this study received no financial support.

\section{References}

1. Fernström I, Johansson B. Percutaneous pyelolithotomy. A new extraction technique. Scand J Urol Nephrol 1976;10:257-9.

2. Kallidonis P, Panagopoulos V, Kyriazis I, Liatsikos E. Complications of percutaneous nephrolithotomy: classification, management, and prevention. Curr Opin Urol 2016;26:88-94.

3. Michel MS, Trojan L, Rassweiler JJ, Breda A. Complications in percutaneous nephrolithotomy. Eur Urol 2007;51:899-906.

4. Srivastava A, Singh KJ, Suri A, Dubey D, Kumar A, Kapoor R, et al. Vascular complications after percutaneous nephrolithotomy: are there any predictive factors? Urology 2005;66:38-40.

5. Skolarikos A, de la Rosette J. Prevention and treatment of complications following percutaneous nephrolithotomy. Curr Opin Urol 2008;18:229-34. [CrossRef]

6. Douketis JD, Spyropoulos AC, Spencer FA, Mayr M, Jaffer AK, Eckman $\mathrm{MH}$, et al. Perioperative management of antithrombotic therapy: Antithrombotic Therapy and Prevention of Thrombosis, 9th ed: American College of Chest Physicians Evidence-Based Clinical Practice Guidelines. Chest 2012;141:e326-50S. 